\title{
The Interdisciplinary Training Mode of Master of Fine Arts Professional Degree Talents
}

\author{
Yuanyuan Tan ${ }^{1, *}$ and Dehui $\mathrm{Ye}^{1}$

\begin{abstract}
${ }^{1}$ School of Art \& Design, Guilin University of Electronic Technology, Guilin, 541004, China
\end{abstract} \\ *Corresponding author. Email: tyyshow@126.com
}

\begin{abstract}
At present, the "interdisciplinary training" of graduate education reform is the general trend. In terms of the practical problems such as lack of distinctive talent training features and insufficient innovation ability, this work explored the training mode of interdisciplinary masters of fine arts by taking the awareness of interdisciplinary collaborative innovation as the orientation and relying on the dominant discipline of "electronic information" of the school. Through the establishment of interdisciplinary innovative design, and the traditional direction of art design parallel training direction, the training mode of interdisciplinary masters of fine arts with the application characteristics of electronic information discipline can be constructed, and the coordinated construction of interdisciplinary "industry-discipline" and "teaching-research" can be implemented. Finally, this work put forward the feasible reform plan related to the course system, tutor team, and practical platform.
\end{abstract}

Keywords: Electronic information technology, Master of fine arts, Interdisciplinary training

\section{INTRODUCTION}

Master of Fine Arts (MFA) was established in 2005 in china and has been in practice for 15 years. Through the investigation of some colleges and universities, it is found that the ideal direction of MFA talents cultivation is not to lose their strengths. From a more macro perspective and a more diverse perspective, how can a school reflect its own training value by relying on its own discipline advantages, condensing and cultivating characteristics is a problem that needs to be deeply considered [1]. In addition, the education of MFA talents needs the artistic practice of "keeping pace with the time" and the innovation ability of "surpassing oneself" [2]. The quality of innovative thinking and methods is the key to improve quality. It is not only the urgent need of scientific and technological innovation and economic and social development to enhance graduate students' innovation ability through interdisciplinary training, but also a rule for the growth of innovative talents, which has become an important trend of graduate education reform in all countries around the world [3]. Based on the above understanding, this work proposed to explore the reform path of talent training mode for MFA professional talents with characteristics of "electronic information" guided by the awareness of interdisciplinary collaborative innovation through comparing with the practical problems of talent training in the MFA program and combining with the current trend of graduate education reform.

\section{THE PRACTICAL BASIS OF INTERDISCIPLINARY CULTIVATION OF MFA PROFESSION TALENTS}

\subsection{Comparing with the development trend of art discipline and contemporary design talent training, the existing talent training has some problems of lagging in innovative ideas}

\begin{abstract}
Interdisciplinary has become a characteristic of contemporary scientific development. The boundarycrossing knowledge produced in the process of interdisciplinary integration is a new form of knowledge supply and a new paradigm of knowledge supply-side reform in innovative education. In February 2017, China's Ministry of Education issued the Notice on New Engineering Research and Practice, and explicitly propose to promote the intersection of existing engineering, engineering and other disciplines; In October 2017, the Hiram College put forward the educational concept of "new liberal arts", and integrated new technology into philosophy, literature, language and other courses; Wu Yan, the director of the Higher Education Department of the Ministry of Education, proposed at the 2018 meeting of the Ministry of Education's cooperative education project, that China should comprehensively promote the construction of "new engineering, new medicine, new agriculture, new liberal arts" and form a first-class undergraduate professional cluster with Chinese
\end{abstract}


characteristics and world level covering all disciplines. The connotation of various "new" titles reflects the characteristics of interdisciplinary crossover. Due to the particularity of the design discipline, although China is also trying to cross disciplines in the training of professional MFA talents, the practical innovation of humanities, arts and engineering technology is still insufficient in the process of training. In addition, the Ministry of Education issued the Declaration on the Construction of New Liberal Arts in November 2020 [4], and proposed that talent training should keep up with a new round of scientific and technological revolution and new trends of industrial transformation, serve the new needs of national soft power construction and cultural prosperity and development, actively promote the deep integration of modern information technology such as artificial intelligence, big data and liberal arts majors, and encourage colleges and universities to set up cross-disciplinary and emerging courses, so as to promote professional transformation and upgrading, and realize the deep integration of liberal arts and science disciplines. Based on this, it is also necessary to keep pace with the times and carry out innovative development through the intersection of arts and sciences. The author thinks that the new idea of interdisciplinary development has provided a theoretical basis for engineering colleges to promote the educational reform of MFA majors, which is in line with the interdisciplinary characteristics of design disciplines in the new era. Therefore, the establishment of interdisciplinary training system is the inevitable choice of innovative training mode for graduate students.

\subsection{Comparing the needs of regional economic development and finding the gap between talent training standards and social needs}

The university where the author works is a local university and the talent training of MFA degree should serve the development of regional economy. Therefore, how to catch the fast train of social and economic development to seek development and take the initiative to connect with regional economic development has been a problem. The regional economic development of Guangxi keeps up with the times in promoting the information-based and intelligent industries. In recent years, the Guangxi government has put forward plans such as the 13th FiveYear Plan for the Development of Strategic Emerging Industries in Guangxi (2016-2020) and the Overall Plan for Guangxi to Fully Dock the Guangdong-Hong Kong-Macao Greater Bay Area (2018-2035), so as to accelerate the integration of scientific and technological innovation and promote the industrialization of all kinds of high-tech achievements. However, the knowledge output from the existing talent training program and curriculum system is limited to the scope of knowledge system of design discipline, lacking contents closely related to the development and application of technology of the times, and unable to meet the needs of regional economic development to cultivate interdisciplinary innovation consciousness and technical thinking of design talents. The talent cultivation does not fit well with the regional economic development and the industry demand, so it is imperative to adjust the talent specification from single talent specification to technology integration and diversified development of talent specifications.

\subsection{According to the requirements of master degree evaluation construction, the construction of this site has the deficiency of construction connotation and cultivation characteristics}

The construction of master's degree is closely related to the quality of talent training. Preliminary evaluation index system of standards is made to observe and find the key issues affecting the quality of training from the aspects of condensed discipline direction, teaching staff construction and scientific research ability improvement. First, in terms of the aspects of training and setting up product and service design, digital media design, and national art and design, the third direction focuses on ethnic regional issues. However, the characteristics of other directions are unclear, and the conciseness of the cultivation of characteristic talents is insufficient; second, the support of the teaching staff to the characteristic condensing and the characteristic training is not enough, which is reflected in the lack of subject sources, insufficient research and innovation ability, and insufficient industrial practice. In order to improve the rationality of teacher allocation, this degree site has implemented the mechanism of setting up tutor group throughout the graduate student recruitment and training process, but it is still in the exploratory stage, and no effective joint force has been formed. Besides, due to the lack of discipline participation in engineering and technology-related fields, the team still has some problems in undertaking "problem-solving oriented" research and practice guidance. Third, due to the unfocused research direction, unclear characteristics, and insufficient investment in the platform for cultivating research ability and practical ability, the research ability and level are not improved enough due to the lack of practical training. According to the curriculum setting, thesis selection and practical results over the years, there are few achievements with social influence or discipline influence, which fail to provide effective support for the discipline development of the school. In view of the fact that the school is a university with outstanding advantages in electronic information, the author believe that from the perspective of development, it is a shortcut to improve the quality of the innovative talent training mode to construct the MFA program with electronic information training characteristics through the cross integration of the university's dominant disciplines. 


\section{THE CONSTRUCTION OF THE TRAINING MODEL OF THE MFA PROFESSIONAL DEGREE WITH THE DISTINGUISHED CHARACTERISTICS OF INTERDISCIPLINARY}

"Talent training mode" refers to the sum of the process of carrying out talent education under the guidance of certain modern educational theories and educational thoughts, in accordance with specific training objectives and talent specifications, and with relatively stable teaching content and curriculum system, management system and evaluation method. Faced with the problems of lagging discipline development, low degree of fit with the talent demand of regional economic development and lack of training, this research put forward the interdisciplinary training concept based on the "industry + electronic information discipline" and built the "industry-discipline" linkage "teachingresearch" MFA talents training mode with the characteristic of electronic information (see Fig. 1, optimization through research and practice).

The construction of the training mode of MFA talents with electronic information characteristics focuses on giving full play to the common role of teaching and scientific research, and orderly driving the transfer of interdisciplinary scientific research resources to the training of teaching resources for MFA talents, so as to promote the cultivation of art design talents with interdisciplinary literacy. Among them, the formulation of talent training specifications comes from the needs of the industry. Guided by the employment demand of enterprises in electronic information and artificial intelligence industry, the talent cultivation positioning should serve the employment demand of the mainstream technology. In addition, the formulation of specifications should also match the resources of superior disciplines, find the matching point between the support of superior disciplines and the development trend of the industry, and make the formulation of talent training specifications produce winwin benefits with the same goal. Industry provides a practical platform for talent training, and discipline development builds and continuously improves the interdisciplinary collaborative teaching platform for talent training. At the same time, the practical results produced by the training of MFA professional degree can also be used as interdisciplinary teaching resources to promote other disciplines. With the emergence of new disciplines and the emergence of new needs, strengthening the exchange and integration of various professional knowledge is helpful to cultivate divergent thinking of graduate students, improve innovation discipline and establish innovative thinking consciousness. The research problems of electronic information related disciplines can be used as a supplement to the project training of MFA talents, and the interdisciplinary research problems can be used as the traction of project practice, so as to create a platform environment for training interdisciplinary design talents and promote the improvement of application ability and innovation ability. Through the establishment of interdisciplinary curriculum system to support the knowledge construction of talent training, the curriculum system provided by the existing talent training knowledge structure can be optimized, and the dimension of knowledge can be expanded. Based on multidisciplinary fusion knowledge and driven by scientific research practice innovation, interdisciplinary integration can be promoted in many aspects.

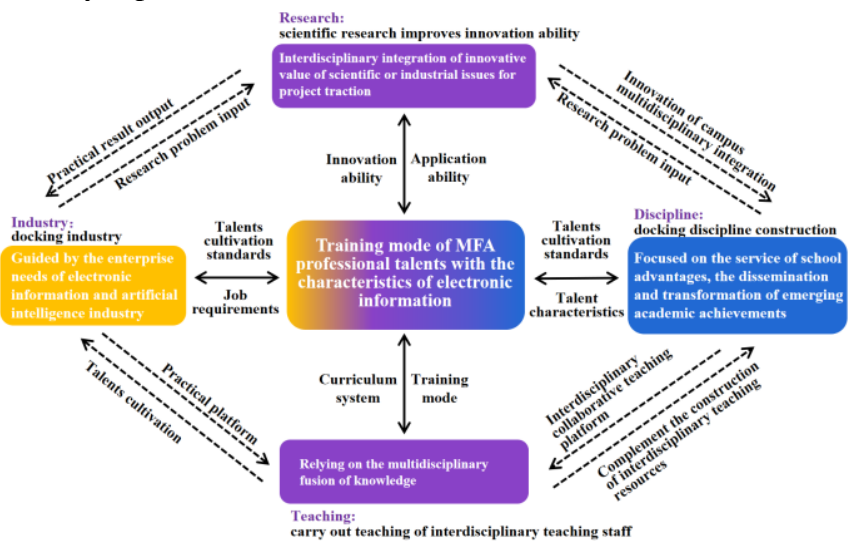

Figure 1. Framework of the talent training model

\section{PRACTICE OF THE TRAINING MODE OF MFA DEGREE TALENTS WITH ELECTRONIC INFORMATION CHARACTERISTICS}

The cross-college collaborative path is one of the mature paths for training interdisciplinary graduate students in American research universities, which is jointly established by colleges to train interdisciplinary graduate students [5]. The college has two different disciplines, including design science and computer application science, which are not entirely based on a single discipline. Although it is an interdisciplinary school, it still faces the problem that the school does not offer courses of related subjects when setting up the interdisciplinary degree program. Based on the above situation, it is a rational choice to seek cooperation with other colleges involved in related disciplines to set up interdisciplinary degree programs. Based on the practical experience of "cross-college collaborative path", and the reform goal of interdisciplinary talent training model, this work studied the reform measures to optimize the curriculum system setting, proposed feasible programs from key links, such as curriculum system, tutor group and innovative practice, and carried out practice verification. 


\subsection{Constructing a course system that integrates the characteristic research and cultivation of "cross-electronic information discipline"}

Setting up the direction of "interdisciplinary innovative design", managing the selection mechanism of top students, and using cross-learning content and practiceoriented training as teaching means can meet the higher learning needs of students through the experience of cutting-edge and challenging technical projects [6]. Focusing on the cultivation of innovation ability, the teaching scope of interdisciplinary knowledge is defined according to the needs of industry development and the development of superior disciplines in the university. It is necessary to reform the curriculum and construct the curriculum training system which integrates the knowledge of electronic information (see Fig. 2 for the construction of the curriculum system).

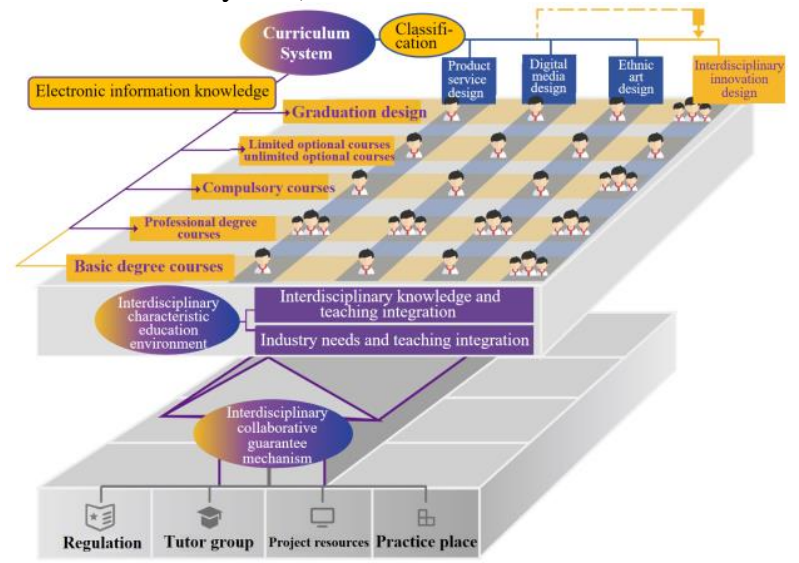

Figure 2. Construction of curriculum system

In view of the characteristics and requirements of MFA talents, while highlighting the characteristics of professional theory and professional practice, the proportion of courses related to the nature of electronic information should be strengthened, so as to encourage students to develop a good habit of interdisciplinary thinking and problem solving while integrating theory with practice. This work studied the application of electronic information related knowledge in basic degree courses, professional degree courses, compulsory courses, limited courses, optional courses, and graduation design, and sorted out the contents of the courses around design innovation, so as to form an electronic information course chain with the characteristics of design disciplines. The curriculum system is designed in different directions and makes guiding choices. Interdisciplinary courses run through all aspects of graduate training in the direction of interdisciplinary innovative design. Other types of courses can choose the relevant content independently. In addition to the electronic information subject knowledge related courses required for professional degree courses, other types of courses can choose relevant contents independently. The form of credits can guide graduate students in non-interdisciplinary innovative design to participate in interdisciplinary workshops or cooperative projects for academic exchange and practice, so as to guide graduate students to develop interdisciplinary thoughts.

\subsection{Promoting the collaborative training mechanism of cross-school and interdisciplinary tutor team}

The cross-college collaborative path is mainly for two or more colleges based on the cross-discipline postgraduate training. As the leading party of interdisciplinary graduate degree programs, a certain college usually absorbs teachers from cooperative colleges to form an interdisciplinary faculty team to jointly provide interdisciplinary courses; the faculty and the curriculum of the partner colleges provide a key complement to the discipline resources [5]. The cross-college tutor team model implemented in this study is an objective demand for the training of master's degree students in art major under the background of new engineering and new liberal arts. The model of tutor team is an effective way to achieve interdisciplinary. Under the background of university-level cooperation and universityenterprise cooperation, a reasonable and effective mechanism should be explored to establish a tutor team, and cross-school and cross-disciplinary collaborative guidance and practice should be carried out through the platform of school-level and university-level joint training base for graduate students. The traditional research direction is tutor group, and teachers are reorganized. The new interdisciplinary tutor group can be established, the interdisciplinary training assignment can be signed, and graduate students can be trained in parallel with the traditional research direction tutor group. In addition, a cross-school and cross-disciplinary research studio (center) has been established to provide a training environment for new graduate students in interdisciplinary innovative design. Establishing a cross-school and cross-disciplinary communication mechanism for the tutor team can manage the selection, guidance and assessment of the tutor team members, and formulate relevant regulations. At the same time, it is also necessary to establish perfect supervision mechanism and examination and reward mechanism, set up interdisciplinary academic committee at college level, deal with academic differences scientifically, hold academic exchange activities among academic teams regularly, and carry out cross-college and interdisciplinary cooperative training.

\subsection{Building an innovative practical platform of interdisciplinary integration}

It is necessary to sort out the conditional resources of interdisciplinary sharing and integration (see Fig. 3), and build the practice platform. For one thing, relying on the on-campus laboratory, research platform and off-campus graduate practice base of this major, it provides students 
with the opportunity to integrate multidisciplinary knowledge and practice project management, and carries out "interdisciplinary project style" scientific research discipline; for another, it actively engages in "double integration" with electronic information related industries and scientific research institutions of relevant advantageous disciplines of the university, and carries out continuous cooperation and academic exchanges, so as to provide "double integration" and high-quality practice conditions for the cultivation of MFA graduate students. The operation of the platform is guided by interdisciplinary projects. One part provides stable projects for students in interdisciplinary innovative design direction, and the other part provides random projects for students (who are interested) in existing training direction. This work took "Special Design" and "Professional Practice" as the reform experiment, carried out the collaborative practice of interdisciplinary project teaching, and explored the operating mechanism of the innovation practice platform. Through the accumulation of interdisciplinary research practice cases year by year, the sustainable development of project teaching resources can be built, and the "sharing and co-construction" mechanism of teaching resources can be gradually improved.

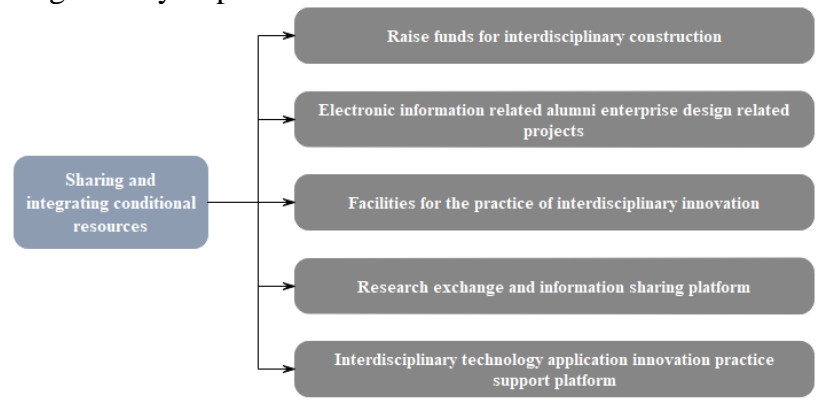

Figure 3. Conditional resources

\section{CONCLUSION}

This research focused on the reform goal of improving the innovation ability of MFA talents, reconstructed the talent training scheme through the path of interdisciplinary cooperative training, improved the overall structure of the curriculum system, optimized the composition of each part of the curriculum system, and formulated the reform measures of cross-college and interdisciplinary tutor team. Through the practice of reform, it is found that the most effective training measures include interdisciplinary courses and seminars, multidisciplinary courses, interdisciplinary team cooperation research, mentor team guidance and other practical activities, which is of great benefit to enhance the awareness and ability of interdisciplinary collaborative innovation of graduate students. However, in the process of reform practice, the problem of poor sustainability in the joint training of crossschool and cross-disciplinary mentor teams have been exposed, which should be paid attention to in the future.

\section{ACKNOWLEDGMENT}

This work was supported by Innovation Project of Guangxi Graduate Education (JGY2020074).

\section{REFERENCES}

[1] Zhou Xing. Considerations on the Training of Master of Arts [J]. Degree and Postgraduate Education, 2007 (06): 9-12.

[2] Ji Yalin. Several Problems to Be Grasped in the Education of Master of Arts [J]. Hundred Schools in Arts, 2008, 24 (S2): 288-289+299.

[3] Zhou Yezhong. Considerations on Interdisciplinary Training of Graduate Students [J]. Degree and Postgraduate Education, 2008 (07).

[4]http://www.moe.gov.cn/jyb_xwfb/gzdt_gzdt/s5987/2 02011/t20201103_498067.html.

[5] Li Bingqian. Study on the System of Interdisciplinary Graduate Training in American Research Universities [D]. China University of Geosciences, 2019.

[6] Chen Yan, Deng Ke, Xu Limei, Li Hui. Exploration on the Reform of Interdisciplinary Cross-practice Teaching for Top Students [J]. Education and Teaching Forum, 2020 (37): 182-183. 